\title{
Upaya Penjaminan Mutu Pendidikan Melalui Akreditasi Sekolah Di 9 SDN Di Wilayah Kabupaten Lamongan
}

\author{
Zainal Aqib \\ Dosen Sekolah Tinggi Ilmu Tarbiayah Muhammadiyah Paciran Lamongan \\ Email: aqib84@yahoo.co.id
}

\begin{abstract}
Expedient in progress the National Education Quality in a order to hoped that suitable with "UU No. 20 Th 2003" about the National Education system, need to do improving all at once to constructive. The control education quality system, that given with pass acridity. Acridity be held for constant the proper of program and school education unite in every ladder and kind of education. Acridity to program and education unite be held by national acridity board. Based above, is "what with have school acridity can guarantee education quality in the nine SDN in Lamongan regency?" The direction of observation is to give information about the popper of school or program that to do standard national education. If advantage that hoped from this result of PTS like statement for school at expedient improving quality and program of improving school. The observation be held at 9 SDN at July 2009 with use acridity instrument from BAN $\mathrm{S} / \mathrm{M}$. The observation file be analysis based penscoran technique and progress the result of acridity. This result of PTS is show there is improving value, from sickles 1 and sickles II. The finally result show if the value acridity of 9 SDN, it is about 71-85 with acridity average B. To headmaster, you must constant can improving result acridity four years later.
\end{abstract}

Key word: Quality assurance of education, School Accreditation. 
Upaya meningkatan mutu pendidikan nasional secara bertahap menuju yang diharapkan sesuai Undang-undang Nomor: 20 Tahun 2003 tentang Sistem Pendidikan Nasional, perlu dilakukan pengembangan sekaligus membangun system pengendalian mutu pendidikan, yang salah satunya melalui Akreditasi.

Akreditasi dilakukan dalam rangka menentukan kelayakan progam dan satuan pendidikan sekolah pada setiap jenjang pendidikan. Akreditasi terhadap progam dan satuan pendidikan dilakukan oleh badan akreditasi Nasional sebagai bentuk akuntabilitas public.

Setiap warga mempunyai hak yang sama untuk ,memperoleh pendidikan yang bermutu ( UU Sisdiknas Nomor: 20 Tahun 2003 Pasal 5 ).

Untuk dapat menyelengarakan pendidikan yang bermutu, setiap satuan pendidikan pada jalur formal dan nonformal wajib melakukan penjaminan mutu pendidikan, yang bertujuan untuk memenuhi atau melampaui Standar Nasional Pendidikan, yang dilakukan secara bertahap, sistematis, dan terancam dalam suatu progam penjaminan mutu yang memiliki target dan kerangka waktu yang jelas ( PP Nomor 19 Tahun 2005 Pasal 91 ). Pemerintah melakukan akreditasi pada setiap jenjang dan satuan pendidikan untuk menentukan kelayakan progam dan atau satuan pendidikan (PP Nomor 19 Tahun 2005 Pasal 86 )

Dalam rangka menuntaskan Renstra 2005-2009 dan menyongsong Renstra 2010-2014, BAN-S/M telah dapat menyelesaikan tiga perangkat akreditasi berdasarkan 8 Standar Nasional Pendidikan yaitu: Perangkat Akreditasi SD/MI, SMP/MTS dan SMK/MAK, setelah sebelumnya menyelesaikan perangkat akreditasi SMA/MA. Perangkat Akreditasi tersebut telah ditetapkan penggunaanya melalui Peraturan Menteri Pendidikan Nasioanal Nomor 11, 12 dan 13 Tahun 2009, Tanggal 4 Maret 2009, tentang Kreteria dan perangkat Akreditasi SD/MI, SMP/MTS dan SMK/MAK, kreteria dan perangkat akreditasi dimaksud merupakan satu kesatuan yang tidak dapat dipisahkan, meliputi:

1. Instrumen Akreditasi;

2. Petunjuk Teknis Pengisian Instrumen Akreditasi;

3. Instrumen Pengumpulan Data Informasi Pendukung Akreditasi; dan

4. Teknik Penskoran dan Pemeringkatan Hasil Akreditasi. 
Sebagai Konsekuensi dalam menindak lanjuti Permediknas tersebut, BAN/S?M dan Badan Akreditasi Provinsi Sekolah/Madarasah (BAP-S/M) dituntut untuk melaksanakan tugas-tugas secara lebih professional, sehingga dapat meningkatkan kepercayaan berbagai pihak terhadap system akreditasi yang telah dikembangkan sesuai dengan system Pendidikan Nasional.

Selanjutnya BAN-S/M mengharapkan kepada para pengelola dan Pelaksana akreditasi di daerah dapat melaksanakan tugasnya secara professional, adil, transparan, Objektif dan akuntabel. Dan apabila akreditasi dilaksanakan sesuai aturan akan memberikan manfaat bagi upaya peningkatan mutu Pendidikan Nasional di Indonesia.

Dalam rangka penjaminan mutu pendidikan (sekolah), pada bulan Juli 2009, telah dilaksanakan Akreditasisekolah jenjang SD dan TK. Sebanyak 41 SD dan 6 TK diakrediatasi oleh 22 Assesor, yang terbagi 11 Tim(1 Tim 2 orang Assesor).

Dari hasil Akreditasi tersebut, kami mencoba melaporkan dalam bentuk Penelitian Tindakan Sekolah (PTS) dengan Judul “ Penjaminan Mutu Pendidikan “ melalui Akreditasi sekolah di 9 Sekolah Dasar Negeri di wilayah Kabupaten Lamongan Tahun 2009

Berdasarkan latar belakang masalah di atas, , rumusan masalah dalam penelitian tindakan Sekolah ini adalah" Apakah dengan Akreditasi Sekolah dapat menjamin mutu pendidikan di 9 SDN di wilayah Kabupaten Lamongan?"

Masalah-masalah yang diikuti dalam akreditasi Sekolah adalah sesuai dengan instrumen akreditasi yang sebelumnya telah diberikan pada sekolahsekolah, yaitu yang mengacu pada 8 Standar Nasional Pendidikan dengan 157 Pertanyaan :

1. Standar isi (18 Pertanyaan),

2. Standar Proses ( 11 Pertanyaan ),

3. Standar Kompetensi Lulusan (17 Pertanyaan ),

4. standar Pendidik dan tenaga Kependidikan (19 Pertanyaan ),

5. Standar Sarana dan Prasarana ( 25 Pertanyaan ).

6. Standar Pengelolaan ( 20 Pertanyaan ),

7. Standar Pembiayaan ( 25 Pertanyaan ), dan 
8. Standar Penilaian ( 22 Pertanyaan ).

Tujuan penelitian ini adalah :

a. Memberikan informasi tentang kelayakan Sekolah atau progam yang dilaksanakannya berdasarkan Standar Nasional Pendidikan.

b. Memberikan pengakuan peringkat kelayakaan

c. Memberikan Rekomendasi tentang penjaminan mutu pendidikan kepada progam dengan atau satuan dan pihak terkait.

Manfaat penelitian ini adalah :

a. sebagai acuan bagi sekolah dalam upaya peningkatan mutu dan rencana pengembangan sekolah

b. Memotivator agar sekolah terus meningkatakan mutu pendidikan secara bertahap, terencana, dan kompetitif, baik ditingkat Kabupaten/kota, Provinsi, Nasional, bahkan regional dan internasional.

c. Sebagai umpan balik dalam usaha pemberdayaan dan pengembangan kinerja warga sekolah dalam rangka menerapkan visi, misi, tujuan, sasaran, dan progam sekolah.

d. Membantu mengindentifikasi sekolah dan progam dalam rangka pemberian bantuan Pemerintah, Investasi dan swasta dan donator atau bentuk bantuan lainnya.

e. Sebagai bahan informasi bagi sekolah sebagai masyarakat belajar untuk meningkatkan dukungan dari Pemerintah, masyarakat, maupun sektor swasta dalam hal professionalisme, moral, tenaga, dan dana.

f. Membantu sekolah dalam menentukan dan mempermudah kepindahaan peserta didik dari satu sekolah kesekolah yang lain, pertukaran guru, dan kerjasama yang saling menguntungkan.

Untuk menghindari salah pengertian mengenai istilah yang digunakan dalam penelitian dan tindakan sekolah ini, perlu adanya batasan istilah, di antaranya : 


\section{Penjaminan Mutu Pendidikan}

Sesuai dalam PP. Nomor 19 Tahun 2005 Pasal 91 adalah suatu upaya sekolah untuk melaksanakan kegiatan sekolah yang bertujuan untuk memenuhi atau melampaui Standar Nasional Pendidikan ( 8 Standar )

Akreditasi Sekolah

Kegiatan penilaian kelayakan progam dan atau satuan pendidikan berdasarkan kreteria yang telah ditetapkan (PP. Nomor 19 Tahun 2005 Pasal 1).

Dari batasan istilah tersebut diatas dapat dimengerti, bahwa penelitian tindakan ini berfokus pada penjaminan mutu sekolah dari hasil penilaian akreditasi yang berdasarkan 8 Standar Nasional Pendidikan.

\section{KAJIAN TEORI}

\section{Penjaminan Mutu Pendidikan Dalam Sisdiknas}

- Penjaminan Mutu Eksternal : dilakukan oleh berbagai pihak /institusi di luar satuan pendidikan yang secara fomal memiliki tugas dan fungsi berkaitan dengan penjaminan mutu pendidikan baik secara langsung/tidak langsung.

- Penjaminan Mutu Internal : dilakukan oleh masing-masing satuan pendidikan.

Kedua model pendekatan tersebut, sungguhpun dapat dibedakan, tetapi memiliki keterkaitan satu sama lain, termasuk keterkaitan antar institusi eksternal dimaksud.

\section{Penjaminan Mutu Eksternal}

Ada 4 Pilar Pokok Dalam Penjaminan Mutu Eksternal

a) Penetapan Standar Nasional Pendidikan ( Penetapan oleh Menteri; Pengembangan, Pemantauan, dan Pengendalian SNP oleh BSNP) PP 19/2005 pasal .76 dan 77 .

b) Pemenuhan SNP pada setiap satuan pendidikan (oleh Pemerintah Provinsi, Pemerintah Kabupaten /Kota, LPMP, dan institusi pembina pendidikan Pusat), PP 19/2005 pasal 92.

c) Penentuan Kelayakan Satuan/Program (Pengecekan derajat-pemenuhan SNP yang dicapai satuan/program pendididkan ) : melalui penilaian kelayakan satuan/program pendidikan mengacu pada kriteria SNP, sebagai bentuk 
akuntabilitas publik), UU 20/2003 pasal 60, Permendiknas 29/2005 pasal 10 Akreditasi oleh BAN S/M , PP 19/2005 pasal 86 dan 87.

d) Penilaian Hasil Belajar (PHB) dan Evaluasi Pendidikan: Ujian Nasional, USBN, Sertifikasi Lulusan, berbagai bentuk ujian lainnya, dan evaluasi kinerja pendidikan oleh Pusat, Pemerintah Provinsi, Pemerintah Kabupaten/Kota serta Lembaga Evaluasi Mandiri. (PP 19/2005)

3. Penjaminan Mutu Oleh Satuan Pendidikan

1) Pengelolaan satuan pendidikan pada jenjang Pendidikan Dasar dan Menengah menerapkan manajemen berbasis sekolah: kemandirian, kemitraan, partisipasi, keterbukaan, dan akuntabilitas. (PP 19/2005 pasal 49)

2) Satuan pendidikan mengembangkan Visi dan Misi ( Standar Pengelolaan), KTSP (Standar Isi), melakukan penilaian hasil belajar termasuk ujian sekolah, dan evaluasi kinerja masing-masing. (PP19/2005 pasal 65).

3) Satuan pendidikan wajib melakukan penjaminan mutu pendidikan, untuk memenuhi atau melampaui SNP. (PP 19/2005 pasal 91)

\section{Hubungan antar pilar dalam penjaminan mutu eksternal}

Hubungä antar pilar datampenjaminan mutu eksternal

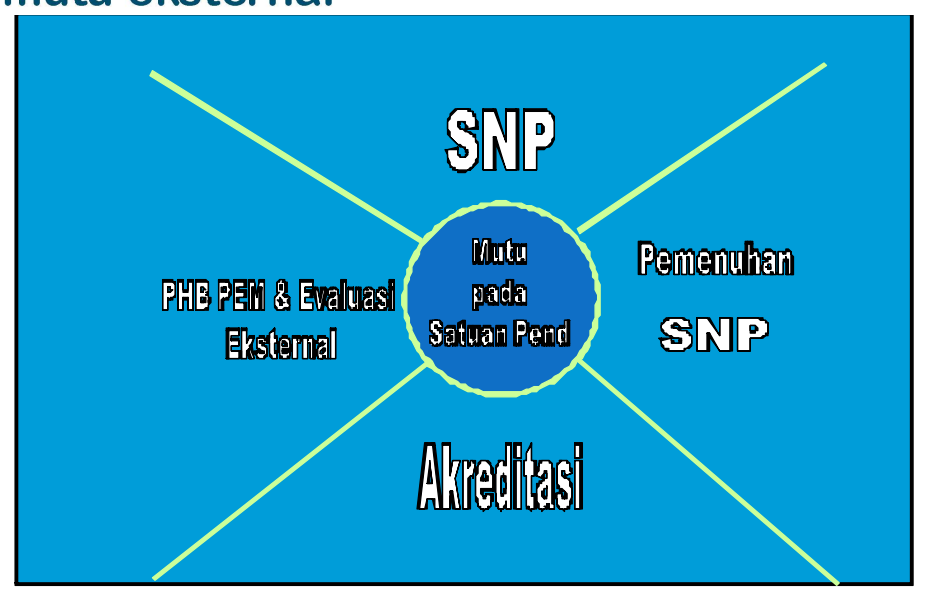

\section{Peran Ban-S/M Dalam Penjaminan Mutu}

- BAN-S/M, memberikan rekomendasi penjaminan mutu pendidikan kepada program dan/atau satuan pendidikan yang diakreditasi, kepada Pemerintah, dan Pemerintah Daerah. 


\section{Akreditasi Sekolah}

1. Rasional

Setiap warga negara berhak memperoleh pendidikan yang bermutu. (UU Sisdiknas No 20/2003, Pasal 5 ayat 1)

Untuk dapat menyelenggarakan pendidikan yang bermutu, setiap satuan/program pendidikan harus memenuhi atau melampaui standar. (PP 19/2005 pasal 91)

Perlu dilakukan AKREDITASI terhadap kelayakan setiap satuan/program pendidikan (PP 19/2005 pasal 81)

2. Dasar Hukum BAN-S/M

1. UU No.20 Tahun 2003 tentang Sisdiknas (Pasal 60).

2. PP No.19 Tahun 2005 tentang Standar Nasional Pendidikan (Pasal 86 dan 87).

3. Permendiknas No.29 Tahun 2005 tentang BAN-S/M.

4. SK. Mendiknas No.064/P/2006 tentang Anggota BAN-PT, BAN-S/M dan BAN-PNF.

3. STRUKTUR HUBUNGAN KERJA AKREDITASI S/M
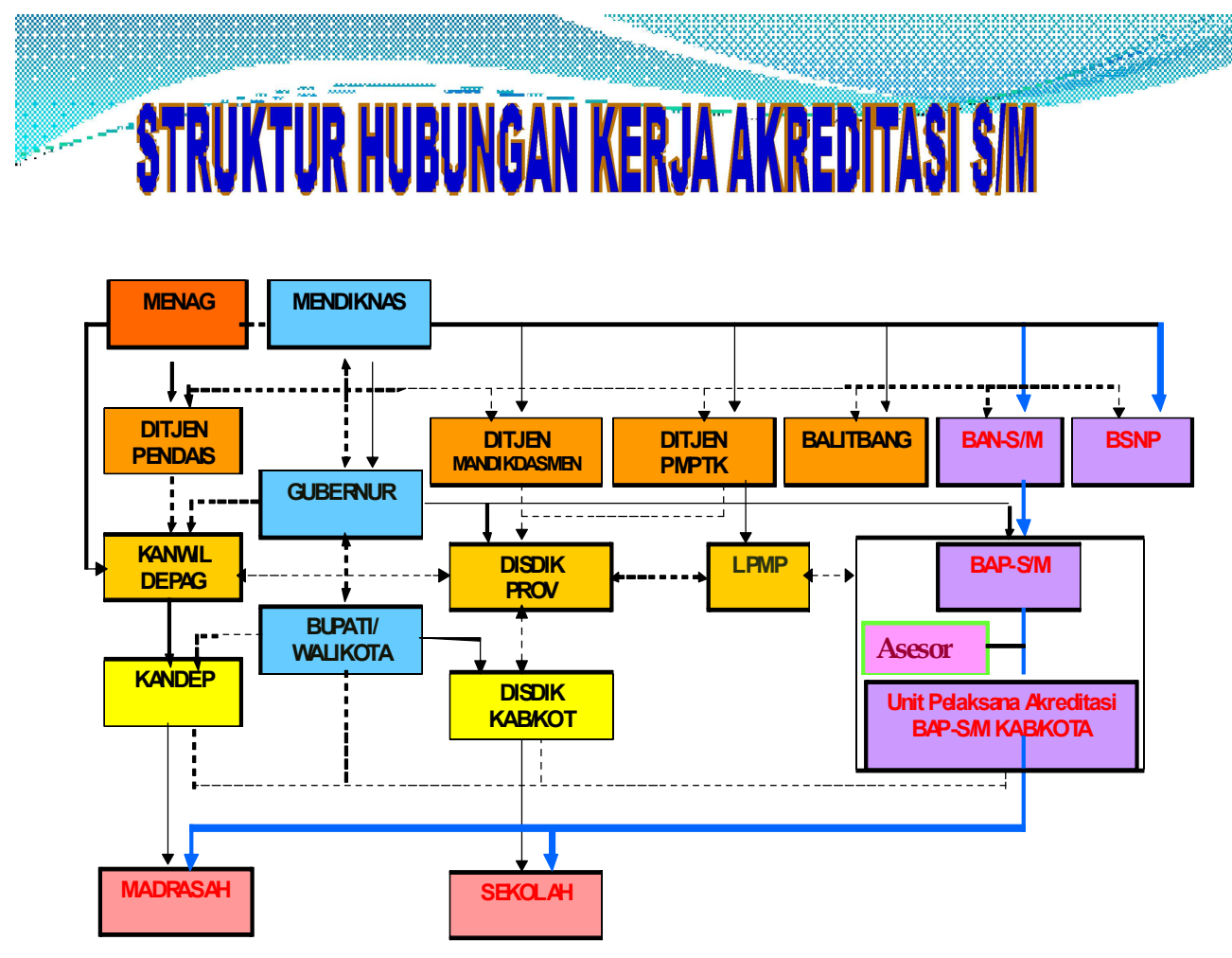
4. Koordinasi Penjaminan Mutu Dan Akreditasi S/M Antar Lembaga Terkait

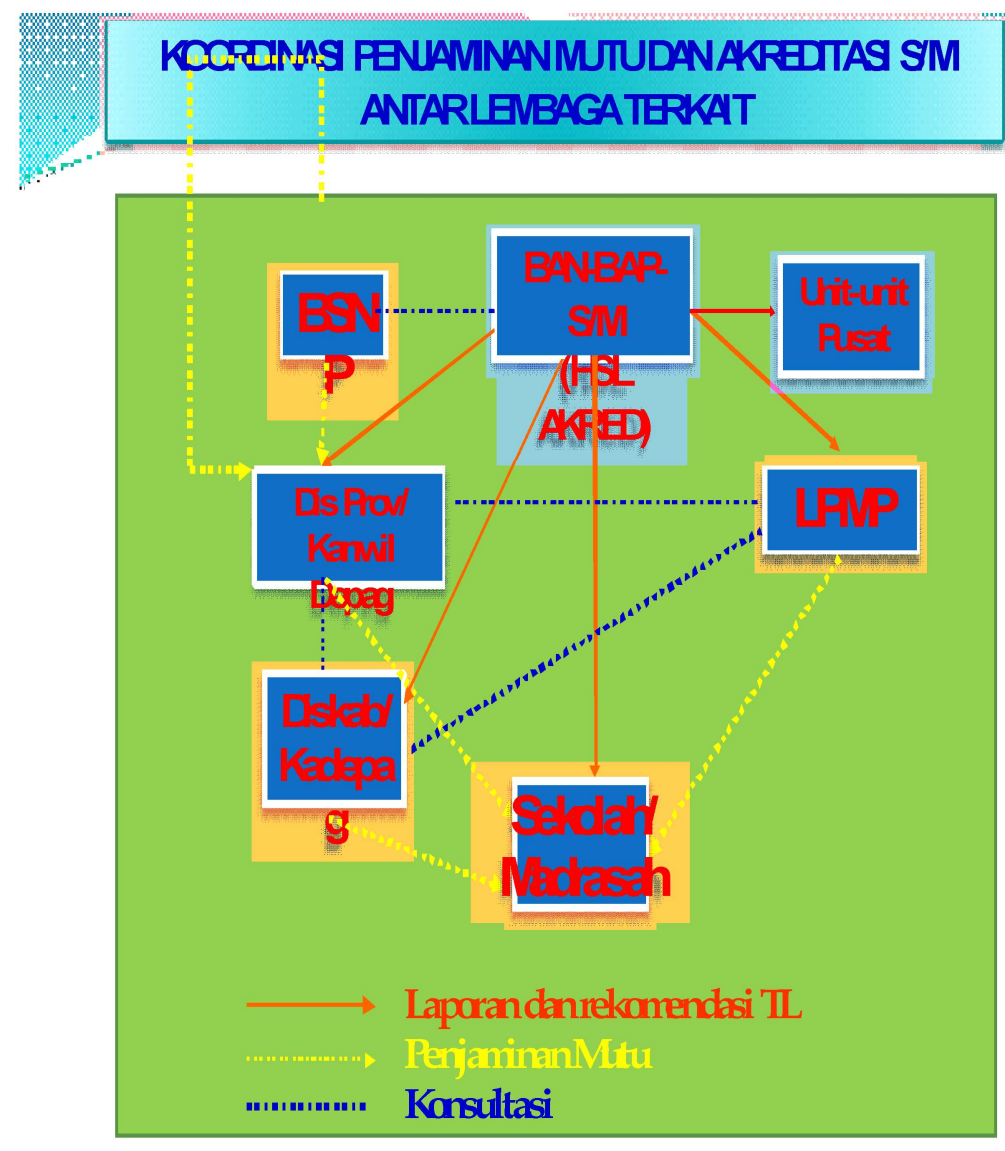

28

5. Pengertian Akreditasi

UU N0. 20/2003 tentang SISDIKNAS

- Akreditasi dilakukan untuk menentukan kelayakan program dan/atau satuan pendidikan pada jalur pendidikan formal dan non-formal pada setiap jenjang dan jenis pendidikan. [Pasal 60 ayat (1)]

- Akreditasi terhadap program dan satuan pendidikan dilakukan oleh pemerintah dan/atau lembaga mandiri yang berwenang sebagai bentuk akuntabilitas publik. [Pasal 60 ayat (2)]

6. AkreditasiS/M Berdasarkan PP No. 19/2005

- Akreditasi adalah kegiatan penilaian kelayakan program dan/atau satuan pendidikan berdasarkan kriteria yang telah ditetapkan [Pasal 1 ayat 21] 
- Pemerintah melakukan akreditasi pada setiap jenjang dan satuan pendidikan untuk menentukan kelayakan program dan/atau satuan pendidikan. [Pasal 86 ayat 1]

- Akreditasi merupakan bentuk akuntabilitas publik dilakukan secara obyektif, adil, transparan, dan komprehensif dengan menggunakan instrumen dan kriteria yang mengacu kepada Standar Nasional Pendidikan [Pasal 86 ayat 3]

7. AkreditasiS/M Berdasarkan Permen No.29/2005

- Akreditasi $\mathrm{S} / \mathrm{M}$ adalah suatu kegiatan penilaian kelayakan suatu $\mathrm{S} / \mathrm{M}$ berdasarkan kriteria yang telah ditetapkan dan dilakukan oleh BAN-S/M yang hasilnya diwujudkan da-lam bentuk pengakuan peringkat kelayakan. [Pasal 1 ayat (5)]

- Untuk melaksanakan akreditasi S/M, pemerintah membentuk BAN-S/M [Pasal 2 ayat (1)]

8. Lingkup Akreditasi Satuan Pendidikan

a. Taman Kanak-kanak (TK)/Raudhatul Atfal (RA).

b. Sekolah Dasar (SD)/Madrasah Ibtidaiyah (MI).

c. Sekolah Menengah Pertama (SMP)/Madrasah Tsanawiyah (MTs).

d. Sekolah Menengah Atas (SMA)/Madrasah Aliyah (MA).

e. Sekolah Menengah Kejuruan (SMK)/Madrasah Aliyah Kejuruan (MAK).

f. Sekolah Luar Biasa (SLB) yang terdiri dari Taman Kanak-kanak Luar Biasa (TKLB), Sekolah Dasar Luar Biasa (SDLB), Sekolah Lanjutan Tingkat Pertama Luar Biasa (SLTPLB), dan Sekolah Menengah Luar Biasa (SMLB).

9. Tujuan Akreditasi Sekolah/Madrasah

a. Memberikan informasi tentang kelayakan $\mathrm{S} / \mathrm{M}$ atau program yang dilaksanakannya berdasarkan Standar Nasional Pendidikan.

b. Memberikan pengakuan peringkat kelayakan.

c. Memberikan rekomendasi tentang penjaminan mutu pendidikan kepada program dan/atau satuan pendidikan yang diakreditasi dan pihak terkait. 
10 Manfaat Akreditasi S/M

a. Acuan dalam upaya peningkatan mutu $\mathrm{S} / \mathrm{M}$ dan rencana pengembangan $\mathrm{S} / \mathrm{M}$.

b. Motivator agar S/M terus meningkatkan mutu pendidikan secara bertahap, terencana, dan kompetitif baik di tingkat kabupaten/kota, provinsi, nasional bahkan regional dan internasional.

c. Umpan balik dalam usaha pemberdayaan dan pengembangan

kinerja warga $\mathrm{S} / \mathrm{M}$ dalam rangka menerapkan visi, misi, tujuan, sasaran, strategi, dan program $\mathrm{S} / \mathrm{M}$.

d. Membantu mengidentifikasi $\mathrm{S} / \mathrm{M}$ dan program dalam rangka pemberian bantuan pemerintah, investasi dana swasta dan donatur atau bentuk bantuan lainnya.

e. Bahan informasi bagi $\mathrm{S} / \mathrm{M}$ sebagai masy. belajar untuk meningkatkan dukungan dari pemerintah, masy, maupun sektor swasta dalam hal profesionalisme, moral, tenaga, dan dana.

f. Membantu S/M dalam menentukan dan mempermudah kepindahan peserta didik dari satu sekolah ke sekolah lain, pertukaran guru, dan kerjasama yang saling menguntungkan.

11. Fungsi Akreditasi S/M

a. Akuntabilitas, yaitu sebagai bentuk pertanggung-jawaban S/M kepada publik, apakah layanan yang dilakukan dan diberikan oleh sekolah/ madrasah telah memenuhi harapan atau keinginan masyarakat.

b. Pengetahuan, yaitu sebagai informasi bagi semua pihak tentang kelayakan $\mathrm{S} / \mathrm{M}$ dilihat dari berbagai unsur terkait yang mengacu pada standar minimal beserta indikator-indikatornya.

c. Pembinaan dan pengembangan, yaitu sebagai dasar bagi $\mathrm{S} / \mathrm{M}$, pemerintah, dan masyarakat dalam upaya peningkatan atau pengembangan mutu $\mathrm{S} / \mathrm{M}$.

\section{Prinsip Akreditasi S/M}

\section{Objektif}

Akreditasi $\mathrm{S} / \mathrm{M}$ pada hakikatnya merupakan kegiatan penilaian tentang kelayakan penyelenggaraan pendidikan yang ditunjukkan oleh suatu S/M. 
Dalam pelaksanaan penilaian ini berbagai aspek yang terkait dengan kelayakan itu diperiksa dengan jelas dan benar untuk memperoleh informasi tentang kebera-daannya. Agar hasil penilaian itu dapat menggambarkan kondisi yang sebenarnya untuk dibandingkan dengan kondisi yang diharapkan maka dalam prosesnya digunakan indikator-indikator terkait dengan kriteria-kriteria yang ditetapkan.

\section{Komprehensif}

Dalam pelaksanaan akreditasi S/M, fokus penilaian tidak hanya terbatas pada aspek-aspek tertentu saja tetapi juga meliputi berbagai komponen pendidikan yang bersifat menyeluruh. Dengan demikian hasil yang diperoleh dapat menggambarkan secara utuh kondisi kelayakan S/M tersebut.

\section{Adil}

Dalam melaksanakan akreditasi, semua S/M harus diperlakukan sama dengan tidak membedakan $\mathrm{S} / \mathrm{M}$ atas dasar kultur, keyakinan, sosial budaya, dan tidak memandang status $\mathrm{S} / \mathrm{M}$ baik negeri ataupun swasta. $\mathrm{S} / \mathrm{M}$ harus dilayani sesuai dengan kriteria dan mekanisme kerja secara adil dan/atau tidak diskriminatif.

\section{Transparan}

Data dan informasi yang berkaitan dengan pelaksanaan akreditasi S/M seperti kriteria, mekanisme kerja, jadwal serta sistem penilaian akreditasi dan lainnya harus disampaikan secara terbuka dan dapat diakses oleh siapa saja yang memerlukannya.

\section{Akuntabel}

Pelaksanaan akreditasi S/M harus dapat dipertanggungjawabkan baik dari sisi penilaian maupun keputusannya sesuai aturan dan prosedur yang telah ditetapkan.

13. Persyaratan Mengikuti Akreditasi
a. Memiliki surat Keputusan Pendirian/Operasional S/M.
b. Memiliki peserta didik pada semua tingkatan kelas.
c. memiliki sarana dan prasarana pendidikan.
d. memiliki pendidik dan tenaga kependidikan.
e. Melaksanakan kurikulum yang berlaku, dan 
f. telah menamatkan peserta didik.

14. Komponen Akreditasi

Akreditasi mencakup semua (8) komponen dalam Standar Nasional Pendidikan

a) Standar Isi, [Permen 22/2006]

b) Standar Proses, [Permen 41/2007]

c) Standar Kompetensi Lulusan, [Permen 23/2006]

d) Standar Pendidik dan Tenaga Kependidikan, [Permen 13/2007 Ttg Kasek, Permen 16/2007 Ttg Guru, Permen 24/2008 Ttg Tenaga Adm]

e) Standar Sarana Dan Prasarana [Permen 24/2007]

f) Standar Pengelolaan, [Permen 19/2007]

g) Standar Pembiayaan, [PP. 48/2008]

h) Standar Penilaian Pendidikan. [Permen 20/2007]

\begin{tabular}{|c|c|c|c|c|}
\hline No. & Komponen Akreditasi & Nomor Butir & $\begin{array}{c}\text { Jumlah } \\
\text { Butir }\end{array}$ & $\begin{array}{c}\text { Bobot } \\
\text { Komponen }\end{array}$ \\
\hline (1) & (2) & (3) & (4) & (5) \\
\hline 1 & Standar Isi & $1-18$ & 18 & 15 \\
\hline 2 & Standar Proses & $19-29$ & 11 & 15 \\
\hline 3 & Standar Kompetensi Lulusan & $30-46$ & 17 & 13 \\
\hline 4 & Standar Pendidik dan Tendik & $47-65$ & 19 & 15 \\
\hline 5 & Standar Sarana dan Prasarana & $66-90$ & 25 & 11 \\
\hline 6 & Standar Pengelolaan & $91-110$ & 20 & 10 \\
\hline 7 & Standar Pembiayaan & $111-135$ & 25 & 10 \\
\hline 8 & Standar Penilaian Pendidikan & $136-157$ & 22 & 11 \\
\hline \multicolumn{3}{|c|}{ Jumlah } & 157 & 100 \\
\hline
\end{tabular}

\section{METODE PENELITIAN}

Penelitian ini dilaksanakan di 9 lembaga Sekolah Dasar Negeri wilayah Kabupaten Lamongan di 2 Kecamatan yaitu:

1. SDN Pandanpancur III Kecamatan Deket

2. SDN Rejotengah I Kecamatan Deket

3. SDN Tukerto Kecamatan Deket 
4. SDN Sidomulyo I Kecamatan Deket

5. SDN Sidomulyo Kecamatan Deket

6. SDN Majenang II Kecamatan Kedungpring

7. SDN Tenggerejo II Kecamatan Kedungpring

8. SDN Kalen Kecamatan Kedungpring

9. SDN Kandangrejo Kecamatan Kedungrejo

Waktu penelitian dilaksanakan pada bulan Juli Tahun 2009 mulai tanggal 8 Juli hingga tanggal 31 Juli 2009, kegiatan diawali dengan sosialisas/visituasi akreditasi oleh kepala sekolah, yaitu berupa pengisian instrumen akreditasi.kemudian kegiatan visitasi akreditasi oleh assesor dari hasil pengisian instrumen akreditasi oleh kepala sekolah tersebut.

Kreteria penelitian ini merupakan penelitian tindakan, maka pelaksanaanya dilaksanakan secara siklus, yaitu: dua siklus, Siklus-siklus itu merupakan rangkaian yang saling berkelanjutan maksudnya, siklus kedua merupakan kelanjutan dari siklus pertama. Setiap siklusnya selalu ada persiapan, pelaksanaan tindakan, penataan evaluasi, serta refleksi.

Teknik pengumpulan data pada penelitian ini terdiri dari atas empat kegiatan pokok, yakni pengumpulan data awal, data hasil analisis setiap akhir siklus, serta tanggapan lain dari stake-holder sekolah (Triangulasi) terhadap pelaksanaan Akreditasi Sekolah.

Data yang telah terkumpul kemudian dianalisis dengan menggunakan analisis kualitatif dan kuantitatif, analisis kuantitatif digunakan sekolah dengan perubahan prilaku peneliti/Assesor dalam melaksanakan akreditasi/visituasi . adapun analisis kuantitatif digunakan untuk mengetahui keberhasilan sekolah berdasarkan 8 standar nasional pendidikan, telah ditetapkan instrumennya oleh BAN S/M.

Adapun peringkat keberhasilan Akreditasi Sekolah adalah apabila Sekolah/Madarasah memperoleh:

1. Peringkat Akreditasi A (Amat Baik(, jika Nilai Akhir (NA) lebih besar atau sama dengan $86(86 \leq \mathrm{NA} \leq 100)$ 
2. Peringkat Akreditasi B (Baik(, jika nilai akhir lebih besar atau sama dengan 71 sampai $85(71 \leq \mathrm{NA} \leq 85)$

3. Peringkat akreditasi C(Cukup baik), jika Nilai Akhir lebih besar dari atau sama dengan 56 sampai dengan $70(56 \leq \mathrm{NA} \leq 70)$

\section{HASIL PENELITIAN}

Berdasarkan pemantauan selama pelaksanaan dan tindak lanjut penelitian, tindakan ini di peroleh berbagai data selama akreditasi sekolah,

Kebenaran Data sesuai instrumen akreditasi tentang 8 standar Nasional Pendidikan Gambaran yang merupakan hasil dan temuan penelitian 
Hasil akreditasi siklus 1 :

REKAPITULASI NILAI AKHIR HASIL AKREDITASI

\begin{tabular}{|c|c|c|c|c|c|c|c|c|c|c|c|c|c|c|}
\hline \multirow{4}{*}{$\begin{array}{c}\mathrm{N} \\
\mathrm{o}\end{array}$} & \multirow{4}{*}{ Nama Sekolah } & \multirow{4}{*}{ NSS } & \multirow{4}{*}{ ALAMAT } & \multirow{4}{*}{ NAMA ASESOR } & \multirow{2}{*}{\multicolumn{8}{|c|}{ Nilai Komponen Skala Ratusan }} & \multirow{4}{*}{$\begin{array}{l}\text { Nilai } \\
\text { Akhir }\end{array}$} & \multirow{4}{*}{$\begin{array}{l}\text { Pering } \\
\text { kat }\end{array}$} \\
\hline & & & & & & & & & & & & & & \\
\hline & & & & & \multicolumn{8}{|c|}{ Yang Sudah Dibulatkan } & & \\
\hline & & & & & 1 & 2 & 3 & 4 & 5 & 6 & 7 & 8 & & \\
\hline 1 & $\begin{array}{l}\text { SDN } \\
\text { Pandan Pancur }\end{array}$ & $\begin{array}{l}101050 \\
702030\end{array}$ & $\begin{array}{l}\text { Pandan Pancur } \\
\text { Deket }\end{array}$ & $\begin{array}{l}\text { 1. Drs. H. Zainal Aqib, M .Pd } \\
\text { 2. Drs. Bambang Suwito, M.Pd. }\end{array}$ & 91 & 84 & 86 & 85 & 75 & 34 & 90 & 94 & 81 & B \\
\hline 2 & $\begin{array}{l}\text { SDN } \\
\text { Sidomulyo I }\end{array}$ & $\begin{array}{l}101050 \\
702014\end{array}$ & $\begin{array}{l}\text { Sidomulyo } \\
\text { Deket }\end{array}$ & $\begin{array}{l}\text { 1. Drs. H. Zainal Aqib, M .Pd } \\
\text { 2. Drs. Bambang Suwito, M.Pd. }\end{array}$ & 76 & 77 & 72 & 71 & 75 & 26 & 79 & 74 & 70 & $\mathbf{C}$ \\
\hline 3 & $\begin{array}{l}\text { SDN } \\
\text { Sidomulyo II }\end{array}$ & $\begin{array}{l}101050 \\
702032\end{array}$ & $\begin{array}{l}\text { Sidomulyo } \\
\text { Deket }\end{array}$ & $\begin{array}{l}\text { 1. Drs. H. Zainal Aqib, M .Pd } \\
\text { 2. Drs. Bambang Suwito, M.Pd. }\end{array}$ & 82 & 73 & 74 & 76 & 74 & 38 & 77 & 86 & 73 & B \\
\hline 4 & $\begin{array}{l}\text { SDN } \\
\text { Tukkerto }\end{array}$ & $\begin{array}{l}101050 \\
702007\end{array}$ & $\begin{array}{l}\text { Tukkerto } \\
\text { Deket }\end{array}$ & $\begin{array}{l}\text { 1. Drs. H. Zainal Aqib, M .Pd } \\
\text { 2. Drs. Bambang Suwito, M.Pd. }\end{array}$ & 80 & 78 & 84 & 84 & 75 & 28 & 85 & 86 & 76 & B \\
\hline 5 & $\begin{array}{l}\text { SDN } \\
\text { Rejotengah I }\end{array}$ & $\begin{array}{l}101050 \\
702010\end{array}$ & $\begin{array}{l}\text { Rejotengah } \\
\text { Deket }\end{array}$ & $\begin{array}{l}\text { 1. Drs. H. Zainal Aqib, M .Pd } \\
\text { 2. Drs. Bambang Suwito, M.Pd. }\end{array}$ & 86 & 86 & 83 & 85 & 73 & 30 & 82 & 86 & 78 & B \\
\hline 6 & $\begin{array}{l}\text { SDN } \\
\text { Majenang II }\end{array}$ & $\begin{array}{l}101050 \\
711030\end{array}$ & $\begin{array}{l}\text { Majenang } \\
\text { Kedungpring }\end{array}$ & $\begin{array}{l}\text { 1. Drs. H. Zainal Aqib, M .Pd } \\
\text { 2. Drs. Bambang Suwito, M.Pd. }\end{array}$ & 86 & 78 & 83 & 85 & 68 & 35 & 90 & 82 & 77 & B \\
\hline 7 & $\begin{array}{l}\text { SDN } \\
\text { Tenggerejo II }\end{array}$ & $\begin{array}{ll}10 & 1050 \\
71 & 1024\end{array}$ & $\begin{array}{l}\text { Tenggerejo } \\
\text { Kedungpring }\end{array}$ & $\begin{array}{l}\text { 1. Drs. H. Zainal Aqib, M .Pd } \\
\text { 2. Drs. Bambang Suwito, M.Pd. }\end{array}$ & 86 & 78 & 83 & 89 & 71 & 34 & 80 & 86 & 78 & B \\
\hline 8 & SDN Kalen & $\begin{array}{l}101050 \\
711019\end{array}$ & $\begin{array}{l}\text { Kalen } \\
\text { Kedungpring }\end{array}$ & $\begin{array}{l}\text { 1. Drs. H. Zainal Aqib, M .Pd } \\
\text { 2. Drs. Bambang Suwito, M.Pd. }\end{array}$ & 68 & 70 & 69 & 80 & 75 & 29 & 83 & 84 & 71 & B \\
\hline 9 & $\begin{array}{l}\text { SDN } \\
\text { Kandangrejo }\end{array}$ & $\begin{array}{l}101050 \\
711010\end{array}$ & $\begin{array}{l}\text { Kandangrejo } \\
\text { Kedungpring }\end{array}$ & $\begin{array}{l}\text { 1. Drs. H. Zainal Aqib, M .Pd } \\
\text { 2. Drs. Bambang Suwito, M.Pd. }\end{array}$ & 77 & 78 & 67 & 80 & 75 & 30 & 64 & 82 & 71 & B \\
\hline
\end{tabular}

Setelah hasil akhir Akreditasi diketahui, maka refleksinya adalah sebagai berikut:

a. Kepala Sekolah agar melengkapi bukti fisik yang belum ada.

b. Kepala Sekolah dengan dibantu guru dan komite sekolah agar menyikapi atau menentukan strategi terbaik untuk meningkatkan status/peringkat akreditasi.

c. Dengan bimbingan dan pembinaan Pengawas Sekolah, Kepala Sekolah dan Guru menginventarisasikan dengan menlengkapi bukti fisik dari 8 Standar Nasional Pendidikan. 
Hasil akreditasi siklus 2 :

\begin{tabular}{|c|c|c|c|c|c|c|c|c|c|c|c|c|c|c|}
\hline \multirow{3}{*}{ No } & \multirow{3}{*}{ Nama Sekolah } & \multirow{3}{*}{ NSS } & \multirow{3}{*}{ ALAMAT } & \multirow{3}{*}{ NAMA ASESOR } & \multirow{2}{*}{\multicolumn{8}{|c|}{$\begin{array}{c}\text { Nilai Komponen Skala Ratusan } \\
\text { Yang Sudah Dibulatkan }\end{array}$}} & \multirow{3}{*}{$\begin{array}{l}\text { Nilai } \\
\text { Akhir }\end{array}$} & \multirow{3}{*}{ Peringkat } \\
\hline & & & & & & & & & & & & & & \\
\hline & & & & & 1 & 2 & 3 & 4 & 5 & 6 & 7 & 8 & & \\
\hline 1 & $\begin{array}{c}\text { SDN } \\
\text { Pandan Pancur }\end{array}$ & $\begin{array}{l}101050 \\
702030\end{array}$ & $\begin{array}{l}\text { Pandan Pancur } \\
\text { Deket }\end{array}$ & $\begin{array}{l}\text { 1. Drs. H. Zainal Aqib, M .Pd } \\
\text { 2. Drs. Bambang Suwito, M.Pd. }\end{array}$ & 93 & 87 & 87 & 88 & 76 & 35 & 91 & 96 & 83 & B \\
\hline 2 & $\begin{array}{c}\text { SDN } \\
\text { Sidomulyo I }\end{array}$ & $\begin{array}{l}101050 \\
702014\end{array}$ & $\begin{array}{l}\text { Sidomulyo } \\
\text { Deket }\end{array}$ & $\begin{array}{l}\text { 1. Drs. H. Zainal Aqib, M .Pd } \\
\text { 2. Drs. Bambang Suwito, M.Pd. }\end{array}$ & 82 & 81 & 86 & 87 & 76 & 28 & 87 & 90 & 78 & B \\
\hline 3 & $\begin{array}{c}\text { SDN } \\
\text { Sidomulyo II }\end{array}$ & $\begin{array}{l}101050 \\
702032\end{array}$ & $\begin{array}{l}\text { Sidomulyo } \\
\text { Deket }\end{array}$ & $\begin{array}{l}\text { 1. Drs. H. Zainal Aqib, M .Pd } \\
\text { 2. Drs. Bambang Suwito, M.Pd. }\end{array}$ & 88 & 87 & 86 & 88 & 76 & 32 & 82 & 89 & 80 & B \\
\hline 4 & $\begin{array}{c}\text { SDN } \\
\text { Tukkerto }\end{array}$ & $\begin{array}{l}101050 \\
702007\end{array}$ & $\begin{array}{l}\text { Tukkerto } \\
\text { Deket }\end{array}$ & $\begin{array}{l}\text { 1. Drs. H. Zainal Aqib, M .Pd } \\
\text { 2. Drs. Bambang Suwito, M.Pd. }\end{array}$ & 83 & 73 & 77 & 81 & 76 & 25 & 79 & 82 & 73 & B \\
\hline 5 & $\begin{array}{c}\text { SDN } \\
\text { Rejotengah I }\end{array}$ & $\begin{array}{l}101050 \\
702010\end{array}$ & $\begin{array}{l}\text { Rejotengah } \\
\text { Deket }\end{array}$ & $\begin{array}{l}\text { 1. Drs. H. Zainal Aqib, M .Pd } \\
\text { 2. Drs. Bambang Suwito, M.Pd. }\end{array}$ & 78 & 79 & 74 & 72 & 76 & 29 & 81 & 76 & 72 & B \\
\hline 6 & $\begin{array}{c}\text { SDN } \\
\text { Majenang II }\end{array}$ & $\begin{array}{l}101050 \\
711030\end{array}$ & $\begin{array}{l}\text { Majenang } \\
\text { Kedungpring }\end{array}$ & $\begin{array}{l}\text { 1. Drs. H. Zainal Aqib, M .Pd } \\
\text { 2. Drs. Bambang Suwito, M.Pd. }\end{array}$ & 94 & 88 & 88 & 89 & 76 & 36 & 90 & 92 & 83 & B \\
\hline 7 & $\begin{array}{c}\text { SDN } \\
\text { Tenggerejo II }\end{array}$ & $\begin{array}{l}101050 \\
711024\end{array}$ & $\begin{array}{l}\text { Tenggerejo } \\
\text { Kedungpring }\end{array}$ & $\begin{array}{l}\text { 1. Drs. H. Zainal Aqib, M .Pd } \\
\text { 2. Drs. Bambang Suwito, M.Pd. }\end{array}$ & 90 & 88 & 88 & 91 & 76 & 36 & 86 & 96 & 83 & B \\
\hline 8 & SDN Kalen & $\begin{array}{l}101050 \\
711019\end{array}$ & $\begin{array}{c}\text { Kalen } \\
\text { Kedungpring }\end{array}$ & $\begin{array}{l}\text { 1. Drs. H. Zainal Aqib, M .Pd } \\
\text { 2. Drs. Bambang Suwito, M.Pd. }\end{array}$ & 72 & 78 & 76 & 83 & 76 & 29 & 86 & 81 & 74 & B \\
\hline 9 & $\begin{array}{c}\text { SDN } \\
\text { Kandangrejo }\end{array}$ & $\begin{array}{l}101050 \\
711010\end{array}$ & $\begin{array}{l}\text { Kandangrejo } \\
\text { Kedungpring }\end{array}$ & $\begin{array}{l}\text { 1. Drs. H. Zainal Aqib, M.Pd } \\
\text { 2. Drs. Bambang Suwito, M.Pd. }\end{array}$ & 78 & 84 & 68 & 81 & 76 & 32 & 67 & 87 & 73 & B \\
\hline
\end{tabular}

Setelah hasil akhir akreditasi diketahui, maka dapat direfleksikan sebagai berikut:

a. Kepala Sekolah menerima hasil akreditasi dengan percaya diri, sebagai dasar atau pijakan akreditasi mendatang

b. Menindak lanjuti hasil yang kurang dari 8 standar Nasional pendidikan untuk ditindak lanjuti atau melengkapi bukti fisik atau yang belum ada,

c. Kepala Sekala(Stoke-holder), (Pengawas Sekolah dan kepala UPT Dinas kecamatan, untuk menentukan straegi yang baik untuk menghadapi pelaksanaan akreditasi yang akan datang.

d. Tim assesor melaporkan hasil akreditasi ke BAN S/M 
Refleksi hasil akhir dapat dilihat pada table 23 berikut ini

Tabel 24

Hasil Akhir Siklus I dan II

\begin{tabular}{|l|l|l|c|c|}
\hline No & \multicolumn{1}{|c|}{ Nama } & \multicolumn{1}{|c|}{ Siklus I } & Siklus II & Kenaikan \\
\hline 1 & SDN Pandanpancur II & $\mathrm{B}(81.13)(81)$ & $\mathrm{B}(82,92)(83)$ & Naik \\
\hline 2 & SDN Rejotengah I & $\mathrm{C}(69.87)(70)$ & $\mathrm{B}(73,49)(73)$ & Naik \\
\hline 3 & SDN Tukerto & $\mathrm{B}(73.40)(73)$ & $\mathrm{B}(71,57)(71)$ & Naik \\
\hline 4 & SDN Sidomulyo I & $\mathrm{B}(76.27)(76)$ & $\mathrm{B}(78,44)(78)$ & Naik \\
\hline 5 & SDN Sidomulyo II & $\mathrm{B}(78.06)(78)$ & $\mathrm{B}(80,11)(80)$ & Naik \\
\hline 6 & SDN Majenag II & $\mathrm{B}(77.27)(77)$ & $\mathrm{B}(83,14)(83)$ & Naik \\
\hline 7 & SDN Teggererjo II & $\mathrm{B}(77.59)(78)$ & $\mathrm{B}(82,87)(83)$ & Naik \\
\hline 8 & SDN Kalen & $\mathrm{B}(70.56)(71)$ & $\mathrm{B}(73,63)(74)$ & Naik \\
\hline 9 & SDN Kandangrejo & $\mathrm{B}(70.72)(71)$ & $\mathrm{B}(73,06)(73)$ & Naik \\
\hline
\end{tabular}

Dari hasil tabel 23 diatas, tampak ada kenaikan nilai dari siklus I ke siklus

II. Dari kenaikan nilai tersebut, membuktikan bahwa penilaian akreditasi sekolah berdampak positif untuk penjaminan mutu suatu sekolah.

\section{KESIMPULAN DAN SARAN}

\section{Kesimpulan}

Berdasarakan hasil visitasi akreditasi sekolah sikuls I dan Siklus II maka dapat disimpulkan, bahwa :

1. SDN Pandanpancur II, mendapatkan nilai akhir akreditasi 83, status Akreditasi : terakreditasi, dan peringkat Akreditasi: B.

2. SDN Sidomulyo I, mendapatkan nilai akhir akreditasi 78, status Akreditasi: Terakreditasi, dan Peringkat Akreditasi: B

3. SDN Sidomulyo II, mendapatkan nilai akhir akreditasi 80 , Status akreditasi, Terakreditasi dan Peringkat Akreditasi : B

4. SDN Tukkerto, mendapatkan nilai akhir akreditasi 73, Status Akreditasi : Terakreditasi, dengan Peringkat Akreditasi : B 
5. SDN Rejotengah I, mendapatkan nilai akhir Akreditasi 72, status akreditasi : Terakreditasi dan Peringkat Akreditasi: B

6. SDN Majenang II, mendapatkan nilai akhir Akreditasi 83, status akreditasi : Terakreditasi dan Peringkat Akreditasi: B

7. SDN Tenggerejo II, mendapatkan nilai akhir Akreditasi 83, status akreditasi : Terakreditasi dan Peringkat Akreditasi: B

8. SDN Kalen, mendapatkan nilai akhir Akreditasi 74, status akreditasi : Terakreditasi dan Peringkat Akreditasi: B

9. SDN Kandangrejo, mendapatkan nilai akhir Akreditasi 73, status akreditasi : Terakreditasi dan Peringkat Akreditasi: B

Dengan memperoleh Peringkat Akreditasi B ( Baik ), komulatif nilai 71 85, maka dapat disimpulkan juga, bahwa dengan penilaian Akreditasi Sekolah, penjaminan mutu pendidikan akan dapat terwujud.

\section{Saran-saran}

Karena Akreditasi sekolah didasarkan pada instrumen yang bersumber dari 8 Standar Nasional Pendidikan, maka disarankan:

a. 9 SDN yan telah diakreditasi, tetap belajar dan berusaha untuk memperbaiki kinerja sekolah sesuai hasil yang didapat.artinya mempertahankan yang sudah baik, dan menyempurnakan yang kurang menurut 8 Standar Nasional Pendidikan tersebut.

b. untuk menghadapi akreditasi empat tahun mendatang, disarankan agar 9 SDN tersebut tetap menjaga dan meningkatkan kinerja sekolah secara baik.

c. Disarankan tetap adanya koordinasi yang baik, antar warga sekolah tu sendiri, dengan masyarakat, dan dengan Pembina Sekolah Seperti Pengawas Sekolah dengan kantor UPT Dinas Pendidikan Kecamatan, termasuk Kantor Dinas Pendidikan Kabupaten Lamongan.

d. Menciptakan suasana Sekolah yang kondusif, ramah anak, ramah lingkungan, dan ramah masyarakat. 


\section{DAFTAR PUSTAKA}

BAN S/M, 2009, Perangkat Akreditasi SD/MI, Jakarta ; Depdiknas.

Depdiknas, 2003, UU Nomor 20 Tahun 2003 tentang sistem Pendidikan

Nasional, Jakarta.

, 2003, PP Nomor 19 Tahun 2005 tentang Standar Nasional Pendidikan, Jakarta.

, 2005, Permendiknas Nomor 29 Tahun 2005 tentang BAN-S/M, Jakarta.

2009, Permendiknas Nomor 11 tahun 2009 tentang Kriteria dan Perangkat Akreditasi SD/MI, Jakarta.

, 2006, SK Mendiknas Nomor 064/P/2006 tentang Anggota BAN-PT, BAN-S/M dan BAN-PNF, Jakarta.

Zainal Aqib, 2009, Penelitian tindakan Sekolah, Bandung, Yrama Widya. 